13

\title{
Формирование магнитных наноструктур с помощью зонда атомно-силового микроскопа
}

\author{
(C) А.Г. Темирязев, ${ }^{1}$ М.П. Темирязева, ${ }^{1}$ А.В. Здоровейщев, ${ }^{2}$ О.В. Вихрова, ${ }^{2}$ Ю.В. Никулин, ${ }^{3}$ Ю.В. Хивинцев, ${ }^{3}$ \\ C.A. Никитов ${ }^{4,5}$
}

${ }^{1}$ Фрязинский фрилиал Института радиотехники и электроники им. В.А. Котельникова РАН, 141190 Фрязино, Россия

${ }^{2}$ Научно-исследовательский физико-технический институт Нижегородского государственного университета им. Н.И. Лобачевского, 603950 Нижний Новгород, Россия

${ }^{3}$ Саратовский фрилиал Института радиотехники и электроники им. В.А. Котельникова РАН, 410019 Саратов, Россия

${ }^{4}$ Институт радиотехники и электроники им. В.А. Котельникова РАН, 125009 Москва, Россия

${ }^{5}$ Московский фризико-технический институт, 141701 Долгопрудный, Россия

e-mail: temiryazev@gmail.com

Поступило в Редакцию 28 марта 2019 г.

В окончательной редакции 28 марта 2019 г.

Принято к публикации 15 апреля 2019 г.

\begin{abstract}
Представлены примеры использования метода импульсной силовой нанолитографии, выполняемой с помощью зонда атомно-силового микроскопа, для формирования магнитных нанопроводов, наноконтактов, одно- и двумерных решеток с характерными размерами порядка $50-100 \mathrm{~nm}$.
\end{abstract}

Ключевые слова: магнитные пленки, литография, наноструктуры, атомно-силовая микроскопия.

DOI: 10.21883/JTF.2019.11.48349.120-19

\section{Введение}

Использование магнитных материалов для разработки новых типов устройств обработки и хранения информации привлекает значительный интерес исследователей уже много лет. С течением времени появляются новые идеи: предлагается использовать в качестве носителей информации магнитные скирмионы [1], разработать трековую память [2], осуществлять генерацию высокочастотных колебаний под действием спин-поляризованного тока [3], использовать доменные стенки в качестве волноведущих структур [4]. Для того чтобы воплощение этих идей было конкурентоспособным, необходимо обеспечить высокую плотность отдельных элементов устройств, т.е. их размеры должны быть малы. Современная технология позволяет создавать структурированную поверхность с периодом порядка $20 \mathrm{~nm}$ [5], однако это крайне сложный, многоступенчатый и дорогостоящий процесс, в котором последовательно используются такие операции, как электронная литография, направленная самоорганизация блочных сополимеров (directed self-assembly of block copolymers), двойное формирование рисунка с самовыравниванием (self-aligned double patterning), нанопечатная литография (nanoimprint lithography) и ионное травление. Для проведения научных исследований и создания макетов устройств было бы желательно иметь более простые и дешевые методы наноструктурирования. Литография с помощью зонда атомно-силового микроскопа (АСM) может быть в этом плане весьма полезна. В работах $[6,7]$ была продемонстрирована возможность создания магнитных проводников шириной 50-60 nm. АСМ использовался для вскрытия окон в мягкой полимерной маске, в которые далее напылялся слой металла. В работе [8] был представлен альтернативный подход, предложен метод импульсной силовой нанолитографии (ИСНЛ), выполняемой с помощью АСМ зонда, оснащенного острой алмазной иглой. ИСНЛ позволяет проводить механическую обработку твердых материалов, т.е. появляется возможность прорезать канавки непосредственно в металлах и полупроводниках. Резка проводится за счет выполнения серии близко расположенных проколов, подобно движению иглы швейной машинки. Малая ширина прорези позволяет формировать достаточно плотную текстуру, в [8] был продемонстрирован массив канавок на поверхности кремния с периодом $30 \mathrm{~nm}$. В настоящей работе мы хотим показать перспективность использования методики ИСНЛ для исследования магнитных пленок и создания наноструктур на их основе.

Эксперименты проводились при помощи АСМ SmartSPM (AIST-NT). Для механической обработки поверхности использовались зонды с монокристаллическими алмазными иглами D300, SCDprobes. Измерения методами магнитно-силовой микроскопии (MCM) проводились с помощью зондов PPP-LM-MFMR и SSS-MFMR, Nanosensors. 

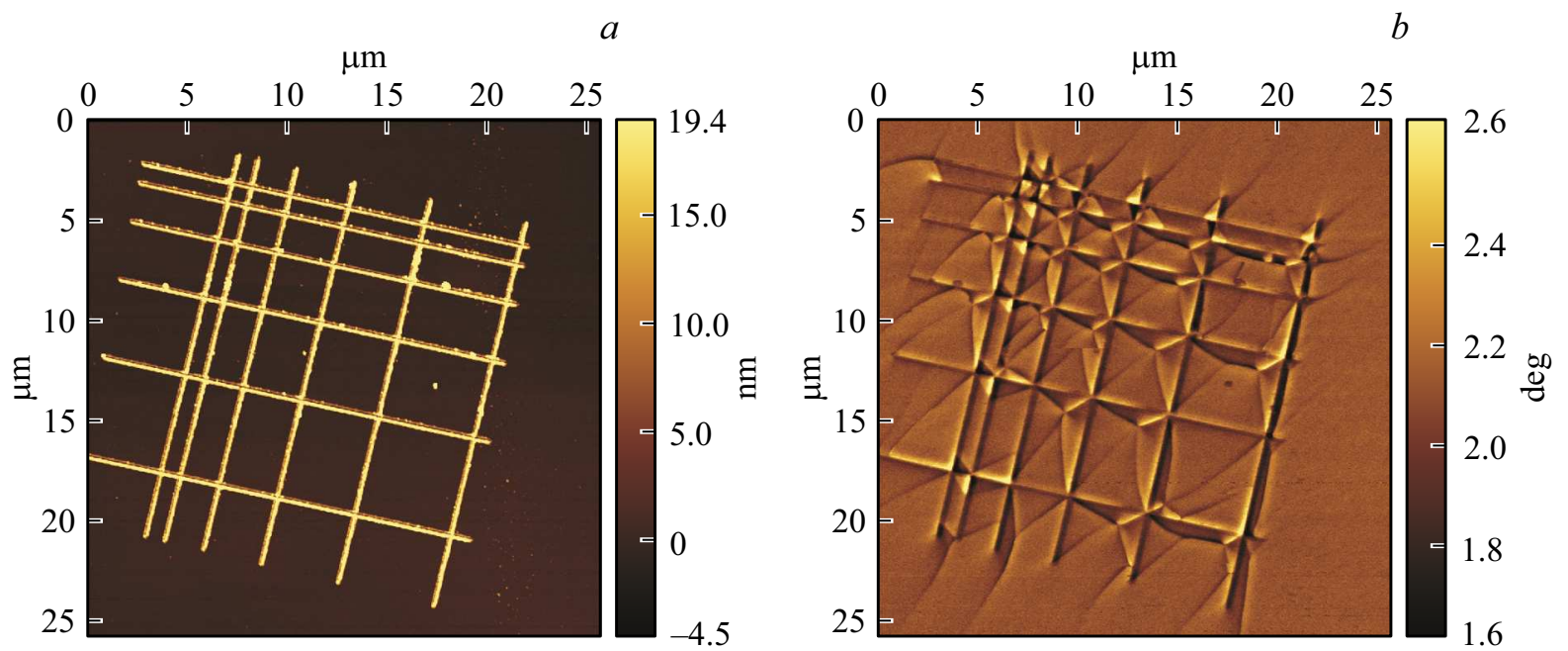

Рис. 1. Топография поверхности $(a)$ и МСМ изображение $(b)$ пленки пермаллоя.

\section{Формирование доменной структуры в пленке пермаллоя}

Характер доменной структуры в магнитных пленках со слабой анизотропией существенно зависит от формы образца. При больших плоскостных размерах пленок домены могут быть очень крупные, порядка нескольких десятков микрон. Такие домены слишком велики для их исследования методами МСМ, однако в поликристаллических пленках внутри доменов часто наблюдается более мелкая периодическая модуляция рябь намагниченности [9]. Для наблюдения „классических“ доменных структур, описываемых теорией [10], как правило, требуется, чтобы минимальный латеральный размер магнитного элемента не превышал нескольких микрон. Обычно для создания таких элементов используется оптическая или электронная литография. Покажем, как эта задача может быть решена методом ИСНЛ. На рис. 1 представлена топография поверхности и магнитное изображение пленки пермаллоя толщиной $50 \mathrm{~nm}$. Зондом АСМ было сделано несколько прорезей во взаимно перпендикулярных направлениях. Светлые полосы на топографическом изображении показывают расположение прорезей (металл, выдавленный из канавок, выступает над поверхностью пленки). Таким образом, мы сформировали 25 элементов - квадратов и прямоугольников с размерами от 1 до $5 \mu \mathrm{m}$. Как видно из МСМ изображения (рис. $1, b)$, это привело к появлению разнообразных доменных структур внутри элементов, различающихся размерами и формой. Изготовленную структуру можно использовать для более подробного МСМ исследования во внешнем магнитном поле. Чтобы проиллюстрировать эту возможность мы сняли около пятисот МСМ изображений при изменении магнитного поля, зарегистрировав несколько циклов перемагничивания. Из полученных изображений был сделан фильм [11]. Анализ полученных данных выходит за рамки этой работы, фильм скорее демонстрирует те направления, по которым можно проводить исследования. Поскольку используемый метод литографии позволяет легко менять геометрию магнитных структур, можно изготавливать специальные структуры для изучения влияния размеров и формы элементов на поле перемагничивания. Потом, выбрав определенный размер, форму и создав массив одинаковых элементов, можно определить разброс полей перемагничивания.

Отметим, что самым мелким элементом на рис. 1 был квадрат со стороной $1 \mu \mathrm{m}$. Далее мы покажем, что метод ИСНЛ позволяет формировать существенно меньшие структуры.

\section{Изготовление нанопроволок и наноконтактов}

При изготовлении токопроводящих структур из исходной магнитной пленки Со толщиной $25 \mathrm{~nm}$ с помощью стандартной оптической литографии и последующего плазменного травления были сформированы контактные площадки, соединенные полоской шириной 5-10 $\mu \mathrm{m}$. Далее с помощью зонда АСМ на этой полоске были выполнены необходимые разрезы. Для формирования нанопроволоки это были два смещенных друг относительно друга разреза (рис. 2), между которыми оставался токопроводящий канал. В случае, изображенном на рис. 2, расстояние между разрезами составляет $100 \mathrm{~nm}$. Чтобы гарантировать надежную электрическую изоляцию по линиям разрезов, при проведении ИСНЛ на контактные площадки подавалось небольшое напряжение $(2-3 \mathrm{mV})$, и по протекающему току контролировалось сопротивление структуры. Мы выполняли несколько проходов зонда по линиям разрезов до тех пор, пока сопротивление не стабилизировалось на новом, более высоком уровне, соответствующем включению в цепь нанопровода. На 

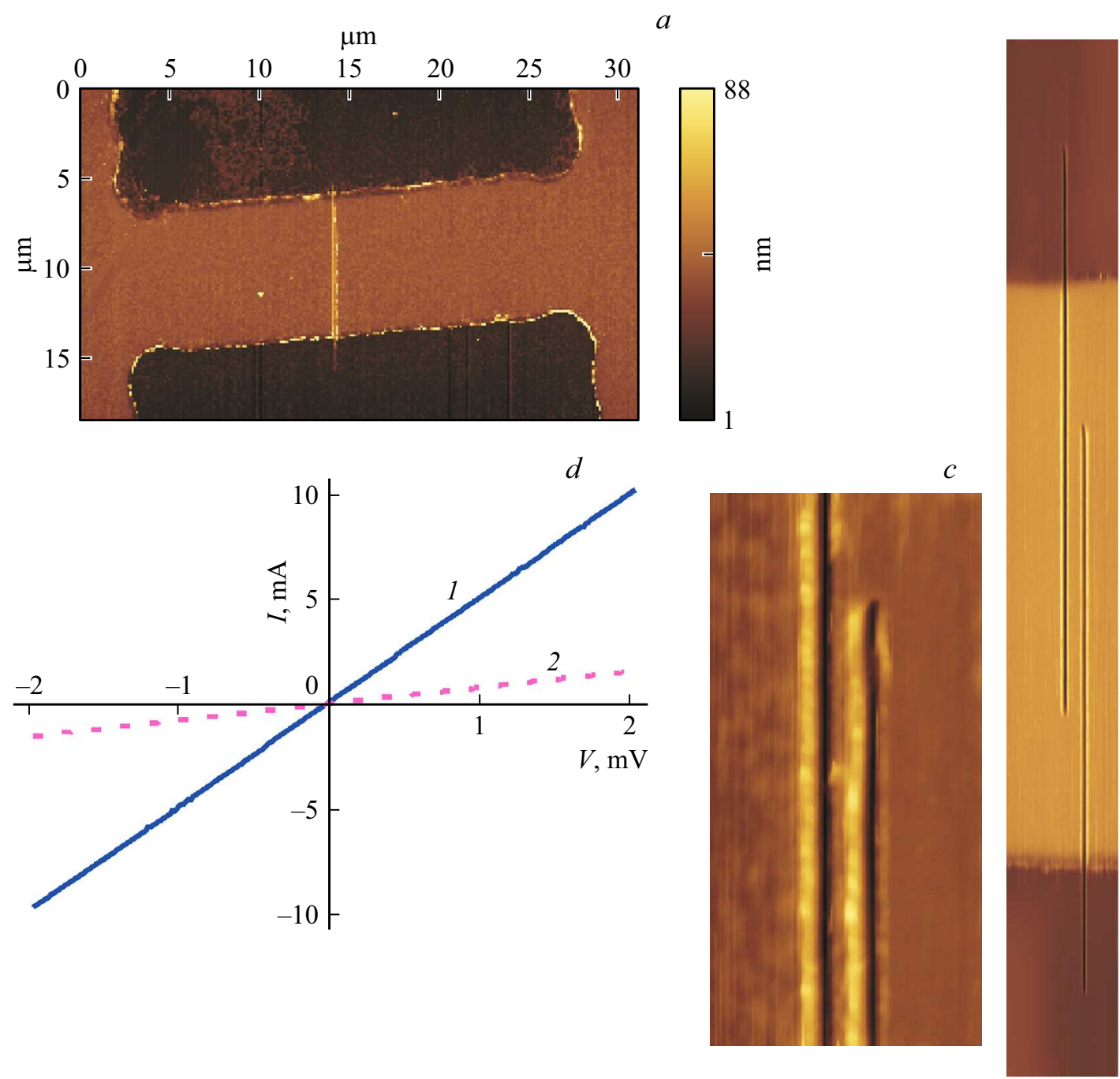

$b$

(1) 

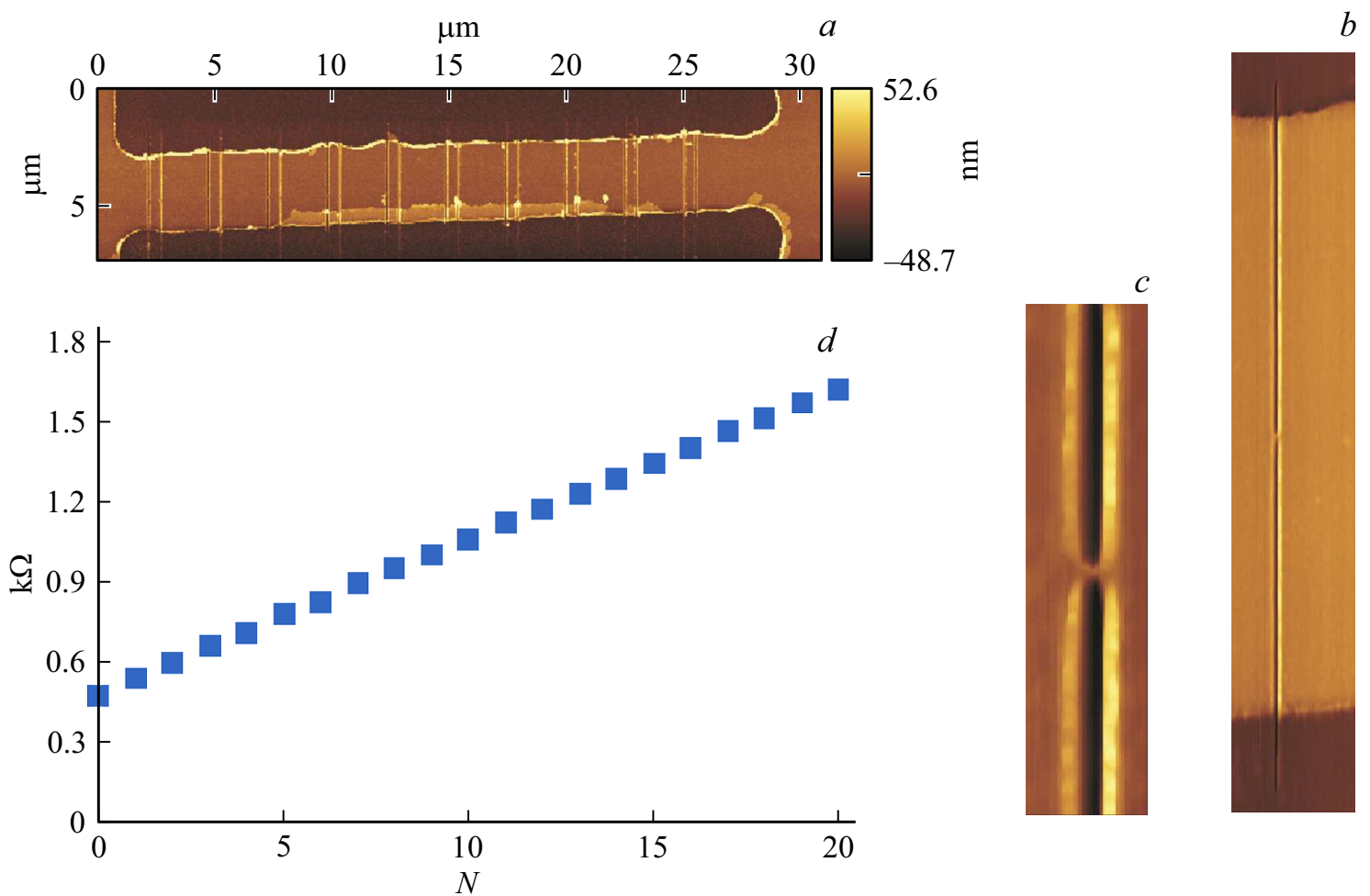

Рис. 3. АСМ изображения: $a$ - общий вид структуры; $b-$ взаимное расположение разрезов; $c$ - наноконтакт (расстояние между разрезами $50 \mathrm{~nm}) ; d-$ зависимость сопротивления структуры от числа наноконтактов.

ли выполнены с использованием пленок CoPt толщиной $8 \mathrm{~nm}$, полученных последовательным напылением тонких слоев Со и $\mathrm{Pt}$ методом электронно-лучевого испарения в высоком вакууме [12,13]. Пленки обладают одноосной анизотропией, перпендикулярной плоскости пленки. В размагниченном состоянии в них наблюдается лабиринтная доменная структура, из которой под влиянием пространственно-локализованного магнитного поля зонда АСМ могут образовываться мелкие изолированные домены, имеющие, по всей вероятности, структуру скирмионов [14]. Мы провели ряд экспериментов по изготовлению периодических решеток на основе таких пленок. На рис. 4, а показан участок, на котором слева имеются разрезы, выполненные методом ИСНЛ, а справа - исходная пленка. Расстояние между канавками $100 \mathrm{~nm}$. На МСМ изображении (рис. 4,b) видно, что в области разрезов распределение намагниченности существенно изменилось. Вместо исходной лабиринтной доменной структуры (справа) мы имеем структуру, в которой намагниченности в двух соседних полосках направлены в противоположные стороны. Магнитная структура напоминает полосовую доменную структуру, однако на месте доменных стенок располагаются разрезы. Это свидетельствует в пользу заметной дипольной связи между полосками. Наличие доменных стенок поперек полосок, видимо, обусловлено их изначальным присутствием в исходной структуре. Распределение намагниченности вдоль полосок можно сделать более однородным, намагнитив, а потом частично размагнитив образец. На рис. 4, с представлено МСМ изображение решетки с периодом $50 \mathrm{~nm}$. После изготовления решетки образец был намагничен до насыщения внешним полем, перпендикулярным плоскости пленки. После снятия поля доменная структура исчезла, пленка была однородно намагничена перпендикулярно ее плоскости. Далее мы просканировали образец в полуконтактном режиме магнитным зондом PPP-LM-MFMR, Nanosensors, имеющим относительно большой магнитный момент. Зонд был намагничен таким образом, что его поле привело к перевороту намагниченности образца практически на всем участке, где не было разрезов. Магнитное изображение, представленное на рис. 4, $c$, было получено при следующем сканировании, выполненном при проходе зонда на некотором удалении от поверхности пленки. Темные области соответствуют исходному направлению намагниченности, а светлые - тем участкам, на которых произошел переворот намагниченности под влиянием поля зонда. В области решетки перемагнитилась каждая вторая полоска, и образовалась периодическая структура. Видимо, за счет дипольного взаимодействия между полосками такая структура энергетически наиболее выгодна.

\section{Формирование двумерной решетки}

Выполнив две серии разрезов во взаимно перпендикулярных направлениях, можно изготовить достаточно 

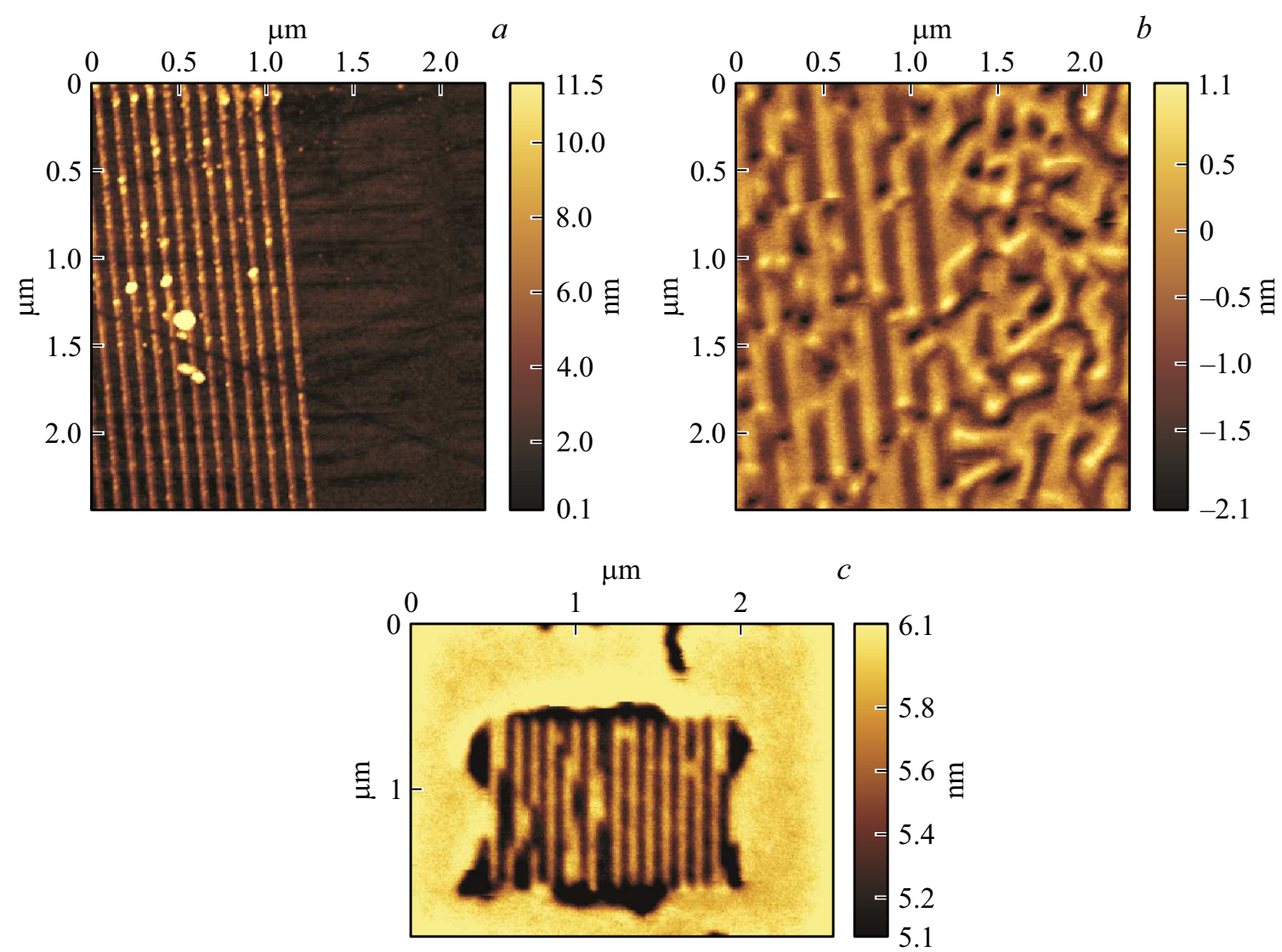

Рис. 4. Топография $(a)$ и $\mathrm{MCM}$ изображение $(b)$ пленки $\mathrm{CoPt}$, период решетки $100 \mathrm{~nm} . c-$ МСМ изображение решетки с периодом $50 \mathrm{~nm}$.
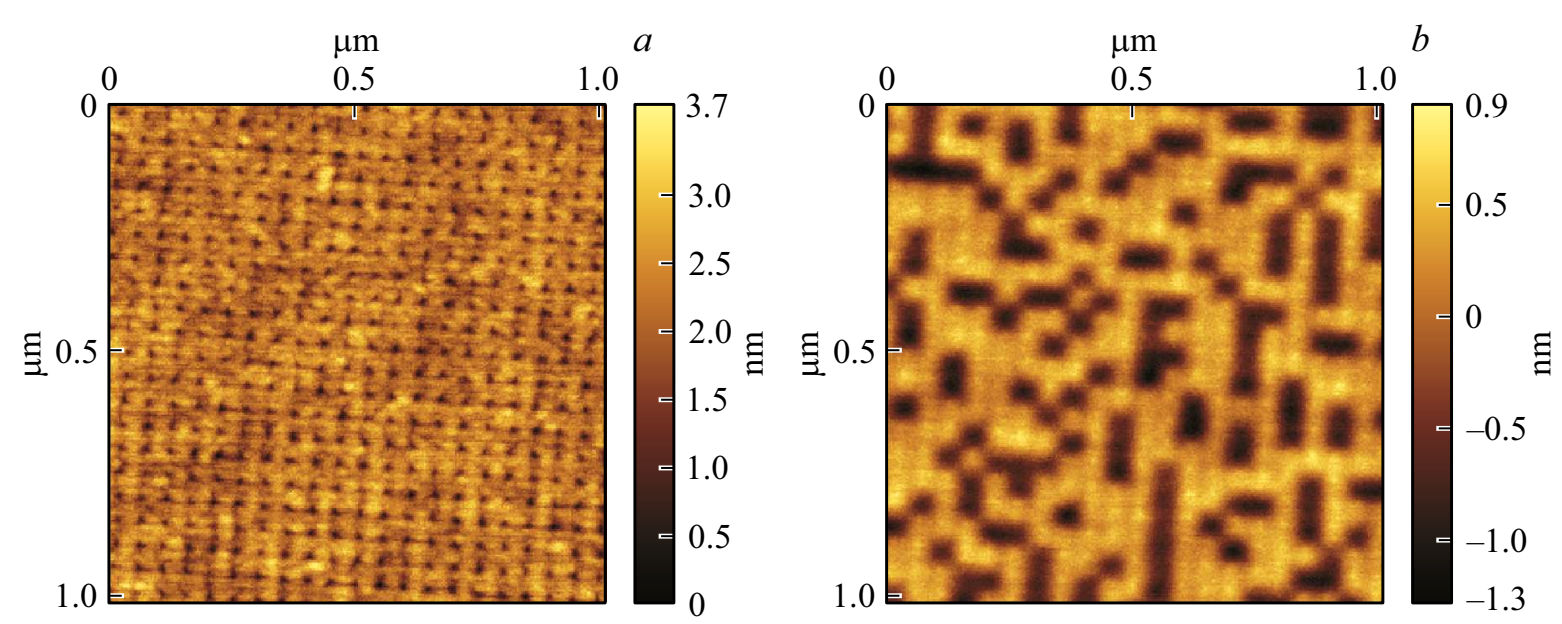

Рис. 5. Топография $(a)$ и МСМ изображение $(b)$ двухмерного массива с периодом $50 \mathrm{~nm}$.

плотную двумерную решетку. На рис. 5 представлен массив квадратных элементов с периодом $50 \mathrm{~nm}$. Как и в предыдущем случае, использована пленка CoPt толщиной $8 \mathrm{~nm}$. Для формирования магнитной структуры мы применили описанную выше процедуру: намагнитили пленку до насыщения, а потом частично перемагнитили полем магнитного зонда. В текстурированной среде магнитостатическое взаимодействие между отдельными элементами приводит к расширению диапазона полей, в которых они перемагничиваются [15]. Под воздействием поля зонда на некоторых участках намагниченность переворачивается, на других остается в исходном состоянии. Чтобы поверхность решетки была более гладкой, мы удалили часть металлических заусенцев, образующихся при резке. Они были счищены при сканировании зондом в контактном режиме. В результате получилась 
достаточно ровная поверхность (рис. 5,a). Углубления соответствуют центрам квадратных элементов, они образуются за счет того, что на краях реза имеются бортики выдавленного металла. Изготовленная решетка использовалась нами для тестирования качества магнитных зондов. Изображения на рис. 5 получены с помощью зонда SSS-MFMR, Nanosensors. Вероятно, подобные структуры могут представлять интерес и для решения других задач, например, для исследования возбуждений в массиве связанных резонаторов.

Следует отметить, что проведенные нами эксперименты показали, что метод ИСНЛ с использованием зондов с монокристаллическими алмазными иглами обладает достаточно высокой стабильностью. При резке металлов зонды длительное время сохраняют свою остроту. Это позволяет выполнять нанолитографию на относительно больших площадях с линейными размерами, ограниченными диапазоном перемещения сканера АCM. Одна из изготовленных решеток состояла из 1600 канавок длиной $90 \mu \mathrm{m}$ каждая. При этом деградации зонда не наблюдалось. Конкретные параметры процесса ИСНЛ (расстояние между точками индентации $\Delta y$ и вертикальное смещение сканера при выполнении прокола $\Delta z$ ) существенно зависят от формы используемой иглы. Их необходимо подбирать для каждого конкретного зонда и требуемой глубины канавки. Типичные значения $\Delta y$ составляли $2-5 \mathrm{~nm}$, величина $\Delta z$ варьировала в очень широких пределах от 15 до $150 \mathrm{~nm}$.

В работе мы привели ряд примеров использования $\mathrm{ACM}$ для формирования магнитных наноструктур. Этот список можно было бы продолжить, поскольку ИСНЛ представляет собой гибкую методику, позволяющую как работать с исходными неструктурированными пленками, так и проводить обработку уже готовых структур. Методика может быть использована для макетирования различных устройств магнитной записи и обработки информации.

\section{Финансирование работы}

Работа выполнена при частичной финансовой поддержке РФФИ (грант № 18-57-76001 ЭРА_а, грант № 18-29-19137_мк), Правительства РФ (соглашение № 074-02-2018-286) (МФТИ), а также проектной части государственного задания Минобрнауки России (№ 8.1751.2017/ПЧ).

\section{Конфликт интересов}

Авторы заявляют, что у них нет конфликта интересов.
[3] Slavin A., Tiberkevich V. // IEEE Trans. Magn. 2008. Vol. 44. N 7. P. $1916-1927$.

[4] Wagner K., Kákay A., Schultheiss K., Henschke A., Sebastian T., Schultheiss H. // Nature Nanotechnology. 2016. Vol. 11. P. 432-436. DOI: https:// doi.org/10.1038/nnano.2015.339

[5] Albrecht T.H., Arora H., Ayanoor-Vitikkate V. etal. // IEEE Trans. Magn. 2015. Vol. 51. N 5. P. 0800342.

[6] Бухараев А.А., Бизяев Д.А., Нургазизов Н.И., Ханипов Т.Ф. // Микроэлектроника. 2012. Т. 41. Вып. 2. C. 90-97. [Bukharaev A.A., Bizyaev D.A., Nurgazizov N.I., Khanipov T.F. // Russ Microelectron. 2012. Vol. 41. P. 78-84. DOI: https://doi.org/10.1134/S1063739712020047]

[7] Бизяев Д.А., Бухараев А.А., Лебедев Д.В., Нургазизов Н.И., Ханипов Т.Ф. // Письма в ЖТФ. 2012. T. 38. Вып. 14. C. 8-15. [Bizyaev D.A., Bukharaev A.A., Lebedev D.V., Nurgazizov N.I., Khanipov T.F. // Tech. Phys. Lett. 2012. Vol. 38. N 7. P. 645-648. DOI: $10.1134 / \mathrm{S} 1063785012070152]$

[8] Temiryazev A. // Diamond \& Related Materials. 2014. Vol. 48. P. 60-64.

[9] Hubert A., Schäfer R. Magnetic Domains. The Analysis of Magnetic Microstructures. Springer-Verlag Berlin Heidelberg, 1998. $696 \mathrm{p}$.

[10] Landau L., Lifshits E. // Phys. Zeitsch. der Sow. 1935. Vol. 8. P. 153-169.

[11] Электронный ресурс. Режим доступа: https://www.researchgate.net/publication/331257057_Remagnetization_of_patterned_permalloy_film_in_an_external_magnetic_field

[12] Здоровейщев А.В., Дорохин М.В., Демина П.Б. идр. // ФТП. 2015. Т. 49. Вып. 12. С. 1649-1653. [Zdoroveyshchev A.V., Dorokhin M.V., Demina P.B. etal. Semiconductors. 2015. Vol. 49. N 12. P. 1601-1604. https://doi.org/10.1134/S106378261512026X]

[13] Здоровейщев А. В., Дорохин М.В., Вихрова О.В., Демина П.Б., Кудрин А.В., Темирязев А.Г., Темирязева М.П. // ФТТ. 2016. Т. 58. Вып. 11. C. 2186-2189. [Zdoroveyshchev A.V., Dorokhin M.V., Vikhrova O.V., Demina P.B., Kudrin A.V., Temiryazev A.G., Temiryazeva M.P. // Phys. Solid State. 2016. Vol. 58. N 11. P. 2267-2270. DOI: $0.1134 / \mathrm{S} 1063783416110391]$

[14] Темирязев А.Г., Темирязева М.П., Здоровейщев А.В., Вихрова О.В., Дорохин М.В., Демина П.Б., Кудрин А.В. // ФТТ. 2018. Т. 60. Вып. 11. С. 2158-2165. DOI: $10.21883 / \mathrm{FTT} .2018 .11 .46657 .12 \mathrm{NN}$ [Temiryazev A.G., Temiryazeva M.P., Zdoroveyshchev A.V., Vikhrova O.V., Dorokhin M.V., Demina P.B., Kudrin A.V. // Phys. Solid State. 2018. Vol. 60. N 11. P. 2200-2206. DOI: $10.1134 / \mathrm{S} 1063783418110318]$

[15] Piramanayagam S.N., Aung K.O., Deng S., Sbiaa R. // J. Appl. Phys. 2009. Vol. 105. P. 07C118.

\section{Список литературы}

[1] Fert A., Reyren N., Cros V. // Nat. Rev. Mater. 2017. Vol. 2. P. 17031.

[2] Parkin S.S.P., Hayashi M., Thomas L. // Science. 2008. Vol. 320. P. 190-194. DOI: 10.1126/science.1145799 